Case Report

\title{
Operational Strategies and Adaptation of RBF Well Construction to Cope with Climate Change Effects at Budapest, Hungary
}

\author{
Zsuzsanna Nagy-Kovács *, Balázs László, Elek Simon and Ernő Fleit \\ Budapest Waterworks Ltd., H-1138 Budapest, Hungary; balazs.laszlo@vizmuvek.hu (B.L.); \\ elek.simon@vizmuvek.hu (E.S.); erno.fleit@vizmuvek.hu (E.F.) \\ * Correspondence: zsuzsanna.nagy-kovacs@vizmuvek.hu; Tel.: +36-30-439-4566
}

Received: 17 September 2018; Accepted: 22 November 2018; Published: 28 November 2018

\begin{abstract}
The objective of this paper is to give an overview on the Hungarian experience of river bank filtration (RBF) systems. The study addresses the conflict, which arises between the stochastic character of river water quantity and quality, and the required standard of drinking-water supply. Trends in water levels, flow, and water quality are discussed, along with technical measures and operational rules that were developed for implementation of RBF systems. This paper also provides an overview of the average lifespan of the wells and operational strategies. The emerging reconstruction and reconditioning needs are highlighted, and existing alternatives are presented. Large-scale infrastructural elements, such as the Danube-based RBF systems, have to be adapted to a changing environment. The increasing frequency of floods and droughts stresses the need to implement climate-adapted RBF systems and related operational strategies. Operational strategies which were developed by the Budapest Waterworks to deal with extreme hydrological scenarios are presented.
\end{abstract}

Keywords: river bank filtration; hydrological trends; sustainable water production; well structure remodeling

\section{Introduction}

The impact of climate change on the hydrological cycle poses a serious challenge to the water industry and society as a whole [1]. Basin flooding and low-water periods of the Danube river are major stress factors for river bank filtration (RBF) systems. Many existing RBF systems can only be operated within a certain range of river-water level [2]. The past century has seen increasing low-water periods for the Danube, whereby the mean water level has reduced by more than 1 meter. Regional interferences (construction of reservoirs in the upstream section) and global/regional climate change (increase of annual water temperatures and critically low water levels) require the development of novel well scheme operation methods [3]. RBF-based water supply systems are exposed to stochastic processes affected by climatic change [4]. Safety and security requirements of water supply contradict these natural processes [5]. Coming up with solutions for these contradictions is a primary focus for the waterworks. Climatic changes have a profound effect on river water levels [6]. More frequent flooding affects not only the flow conditions at RBF systems, but also the quality of the bank filtrate and abstracted water [7]. In addition to this, water demands are fluctuating, land-use patterns, and especially agricultural activities are changing, and energy demands and costs are increasing. However, water quality effects are somewhat tempered in the case of RBF as they are damped, compared to surface water abstraction [8].

During RBF, a significant removal of pollutants occurs in the river bed and the aquifer zone nearest to the river bed, where microbiological activity is high. Due to the changes in river water levels, 
the wetted zone can be increased by up to $50 \%$ under favorable conditions $[9,10]$. In extreme low-water periods, the microbiologically active layer decreases in size, resulting in lower quality of the bank filtrate. Given the potential of the Danube for water supply via RBF in particular, Danubian countries must have a long-term strategy that aims to mitigate problems rooted in global climate change and its aquatic consequences (droughts, floods, etc.) [11,12].

RBF systems can effectively remove pathogenic microorganisms, suspended solids, algae and their toxins, dissolved organic matter, ammonium, disinfection by-product precursors, etc. [13]. The removal efficiency greatly depends on the flow regime of the river; therefore, RBF systems are also sensitive to climate change, although mainly the increased frequencies of extreme water levels [14]. Low-water periods (Figure 1) can cause problems in terms of both water quantity and quality. Long rainy periods can lead to a deterioration of water quality, especially in times of flooding and strong erosion. Under high-flow conditions, the infiltration of river water into the aquifer increases, with a simultaneous increase in the flux of oxygen and organic carbon (3-4 times higher rates), which microorganisms in the active zone (acclimatized to lower flow rates) are not able to fully process. When low-water periods occur, microbiological non-compliances increase, particularly when the temperature of river-bank filtrate is above $15^{\circ} \mathrm{C}$ [15]. In addition to this, a significantly higher number of pathogens is measured in river water during floods. In such cases, water disinfection becomes particularly important. However, compared to surface and groundwater extraction and treatment, RBF is considered to be a more sustainable alternative and less sensitive to climate change [16].

The operation of RBF systems under changing environmental conditions requires a careful analysis of future operational strategies, including the assessment of reconstruction needs at existing RBF systems in Budapest [17].
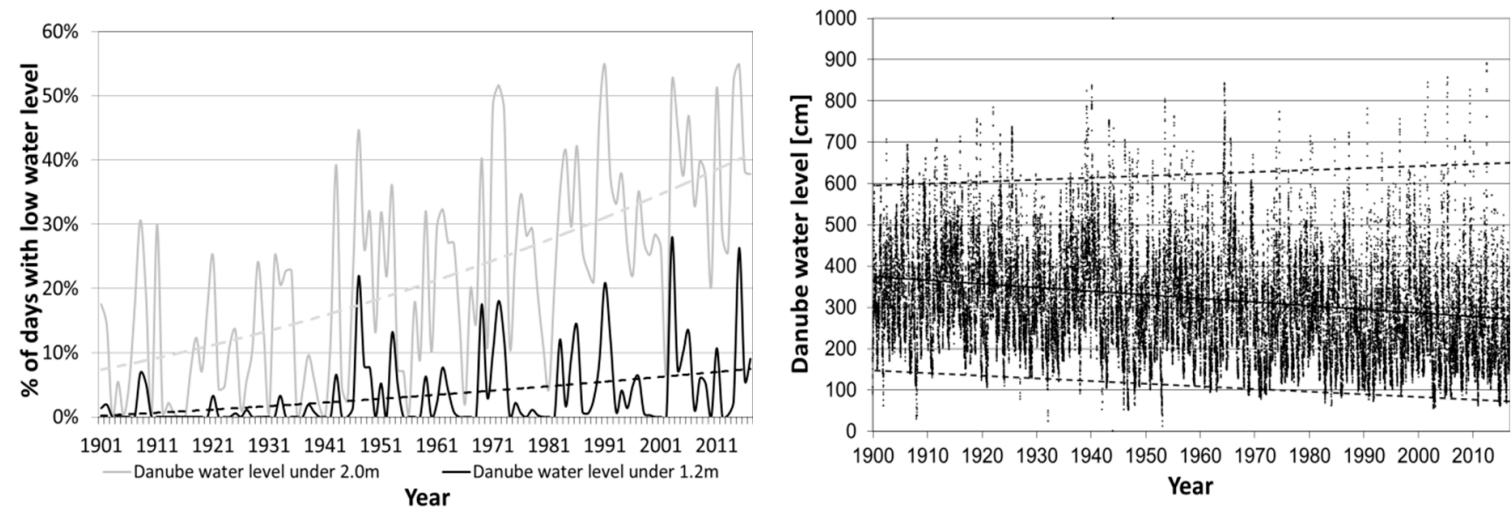

Figure 1. Percentage of days when Danube water levels were below $2 \mathrm{~m}$ and below $1.2 \mathrm{~m}$ (1901-2018) (left); long-term trend of the Danube water level (1646.5 km, Budapest) (right).

The treatment capacity of RBF systems is determined by the following processes:

- Hydrodynamic processes (convective-dispersive transport-transport, mixing, and dilution);

- Mechanical processes (natural filtration);

- Microbiological transformations (biodegradation by microorganisms);

- Physical-chemical and chemical processes (sorption, precipitation, redox processes).

RBF systems are affected by environmental and technical factors [4,7]. Water temperature influences the water's viscosity and thus also the infiltration and flow velocity, resulting in higher abstracted water volumes at higher water temperatures [4]. Temperature also affects biochemical processes and microbial activities, which ultimately affects water quality [8]. The input of waste water into a river determines the quality of the bank filtrate. For example, wells located upstream of the city of Budapest provide excellent water quality, whilst the ones located downstream require iron and manganese removal due to anoxic conditions [3]. 
Directions of water flow into or out of the aquifer are governed by the water levels of the river and the land-side groundwater [10]. Water-level fluctuations have a strong influence on aquifer saturation, the size of the biologically active zone, and the quantity of biofilms. These fluctuations determine the characteristics of the transportation and flow into the unsaturated zone, as this zone has lower removal capability than the saturated one. In the case of high water levels, river water also enters a previous non-wetted zone, resulting in deteriorated water quality [11]. RBF is an ultra-slow filtration process whereby the transport rate is only about $0.1-0.25 \mathrm{~m} /$ day at the bank surface. (For comparison, this value is $5 \mathrm{~m} /$ day at slow sand filtration, and $240 \mathrm{~m} /$ day at rapid sand filtration.)

River-bed regulations can have a negative effect on both the volume and quality of bank filtrate, as evidenced by an example from the Colorado River [6]. In the Hungarian Danube section, gravel dredging has regularly been done to improve navigation conditions. This causes the width of the infiltration zone to decrease, and its depth to change also. River regulations resulted in the decrease of river-bed load transport, and no further coarse fractions were sedimented. River training dams perpendicular to the flow direction also resulted in a siltation of the river bed. This induced anoxic conditions and, consequently, deterioration of water quality by the dissolution of iron and manganese.

The hydrogeological properties of the aquifer zone near the river, such as depth, particle size, transport conditions, hydraulic conductivity ( $\mathrm{K}$ value), mineral composition, and pollution state cannot be influenced by the operator [17]. However, technical parameters can only be managed within certain limits, such as the type of water intake, well distance from the river, produced water volumes, and pump operation.

In the following, based on an overview of the Budapest experience with RBF systems, effects of climate change and changes in water quality will be discussed together with technical measures and operational strategies developed for adaptation of the RBF systems. Furthermore, an overview of construction and lifespans of RBF wells, as well as adaptation measures will be provided.

\section{RBF Site Description}

\subsection{Characteristics of the RBF Site}

The Szentendre Island is situated in the center of Hungary, upstream of Budapest. Its length is $30.85 \mathrm{~km}$, and the average width is $2.3 \mathrm{~km}$, with a maximal width of $3.5 \mathrm{~km}$. Its area is $55.73 \mathrm{~km}^{2}$. Its height above sea level varies between $100.0-123.5 \mathrm{~m}$. The average yearly precipitation is $500-600 \mathrm{~mm}$. The climate represents typical lowland continental conditions. There are no permanent surface water bodies on the island, and temporal wetlands are dispersed over its area. The mean annual air temperature is $11^{\circ} \mathrm{C}$.

\subsection{Hydrogeology}

The site is a separate geographical, hydrological, and ecological unit. From the northernmost tip to the central area, the Szentendre Island is formed by fluvial layers of upper Oligocene clay. On the southern part of the island, Miocene sandy and clay formations can be found. Tertiary sediments are covered by gravel of 7-9 m thickness. The gravel composition of the island is considered to be relatively diverse; however, it can be described as being predominantly sandy and locally intercepted with clay. Fluvial sand is found in the top 3-5 $\mathrm{m}$ of the gravel layer.

The layers of the active watershed area above the clayey substratum are gravelly, sandy, and silty. As the cover is predominantly clay or silt, the gravel layer can be considered as being semi-protected. The groundwater level follows the fluctuations in the Danube water level, and is not influenced by changes of the relief; hence, on the higher part of the island, the groundwater level reaches a depth of 8-10 $\mathrm{m}$ below the surface. Water communicating with the river flow decreases with distance from the river banks. Normally, groundwater flows toward the southern part of the island, while closer to the river bank, the main direction is perpendicular to the river flow. The water balance of the island is determined by the Danube water level. Abstraction wells considerably influence the natural 
groundwater flow and level. Abstracted water is predominantly bank filtrate; however, production can decrease the groundwater level in the inner parts of the island. The aquifer beneath the island is recharged when the river water level is above $2 \mathrm{~m}$ [3].

\subsection{Historical Background}

The construction of RBF wells on Szentendre Island started at the end of the 19th century, when large-capacity shaft wells were constructed on the southern parts of the island (Figure 2). As the population of the capital grew and the relative water consumption increased, drilled wells were installed around the middle of the 20th century. This well type proved to be suitable for the utilization of shallow aquifers. Finally, in the 1970s, mainly horizontal collector wells were constructed on the northern parts of the island.

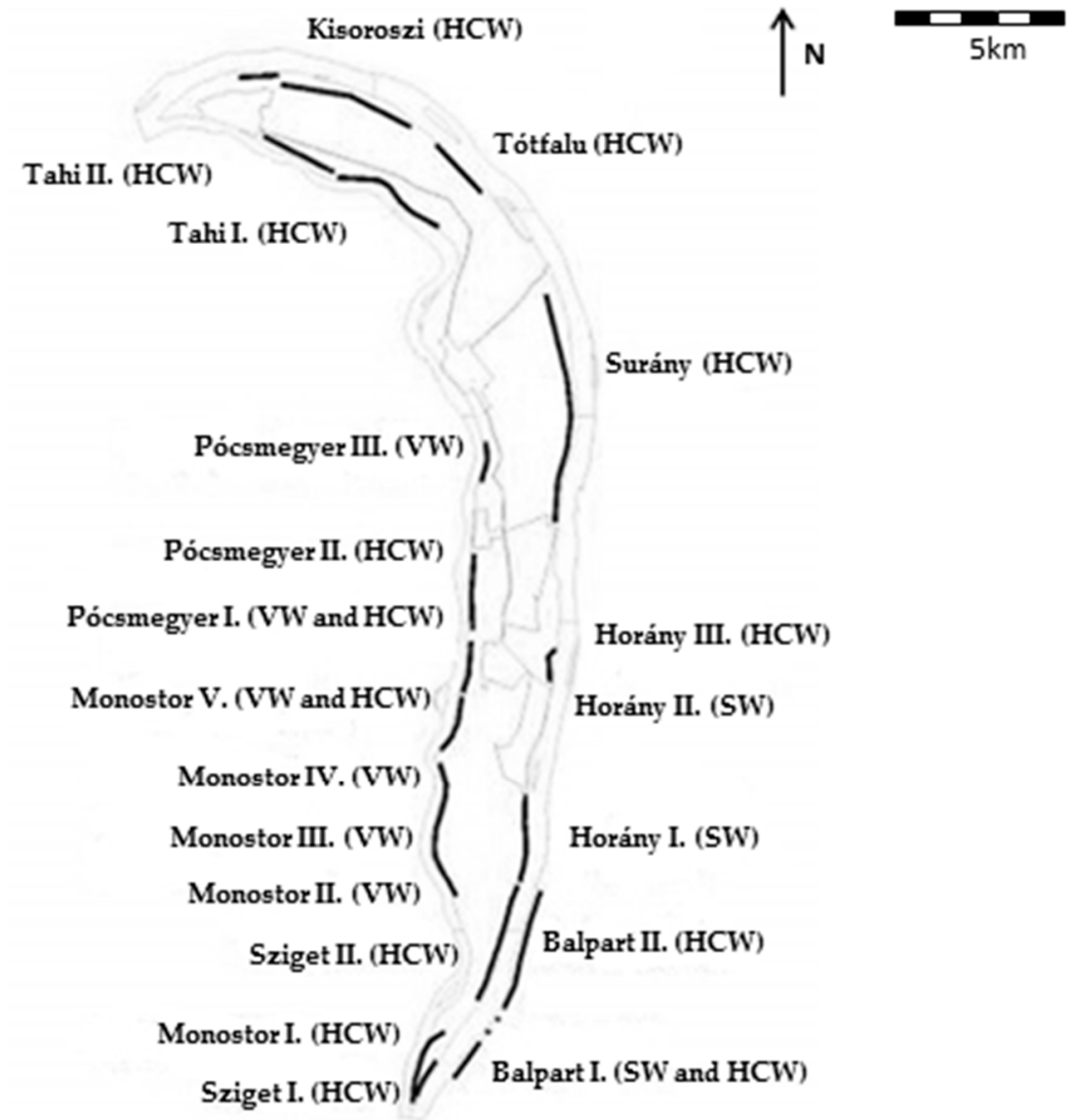

Figure 2. Location and names of well groups of the Budapest Waterworks at Szentendre Island. HCW: horizontal collector well, VW: vertical well, SW: shaft well.

Today, Budapest Waterworks operates 756 RBF wells to supply 1.89 million inhabitants. The wells are predominantly located on Szentendre Island and Csepel Island. The maximum capacity of the RBF systems of Budapest Waterworks is 1.0 million $\mathrm{m}^{3} /$ day, and the average supply is about $456,000 \mathrm{~m}^{3}$ / day. Compared to the average discharge of the Danube River at Budapest of 200 million $\mathrm{m}^{3} /$ day, the water abstraction via bank filtration from the river is, on average, only $0.23 \%$. Figure 3 shows the volume of water fed into the distribution system from 1950 until today. Water consumption followed a continuously increasing trend until 1990, but the economic transition brought changes that influenced both the industrial and public water demands. Decreased industrial activity, an increase in water fees, and the availability of water-saving household devices brought about a change in 
consumption patterns. The dropping trend in consumption levelled out by the mid-90s, and by the first decade of the 21th century the average consumption settled at $120 \mathrm{~L} /$ day/capita.

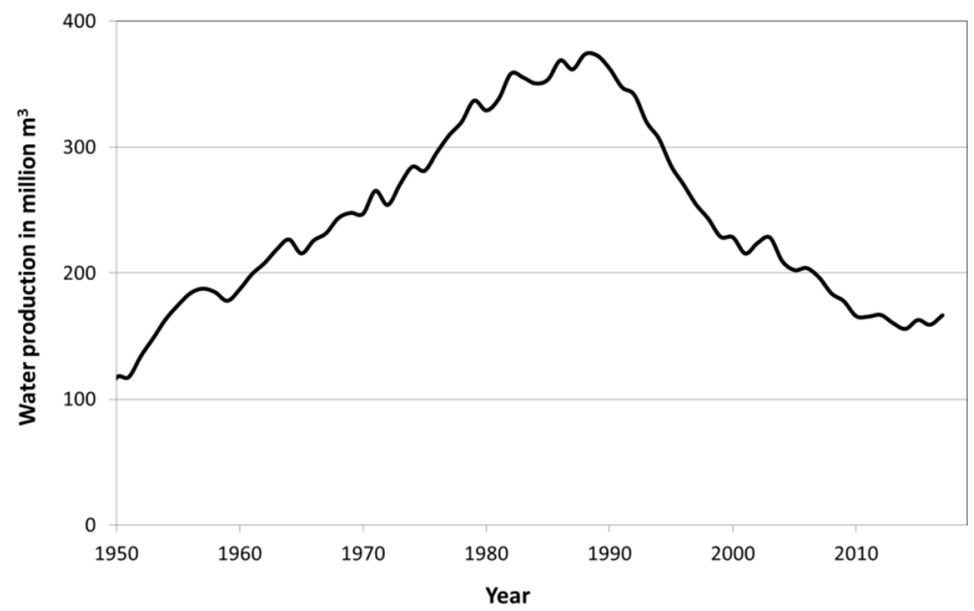

Figure 3. Annual water production from river bank filtration (RBF) schemes in Budapest, 1950-2016.

\section{Discussion of Flow Conditions and Operational Strategies}

The volume of potentially produced drinking water and its quality is largely governed by the already discussed environmental-hydrological factors. The waterworks has limited options to control the listed RBF processes. Infiltration rates and filtration velocity can be controlled by the abstraction rates of the wells. Water quality can also be controlled to a certain degree by controlling the hydraulic conditions of the RBF systems by adjusted well operation.

The present operational strategy has been developed throughout several decades, and continuously adapted to ever-changing requirements and various hydrological scenarios. As an operational rule of thumb, the Budapest Waterworks distinguishes three different operation modes, which are the normal, low-water, and flood conditions, where different challenges are faced and have to be mitigated.

\subsection{Normal Conditions}

Normal conditions are defined by the Danube water level in the range of 120-550 cm (Budapest gauging station, $1646.5 \mathrm{~km}$ ). In this situation, no risk of well inundation is expected and the water production capacity of the wells can meet consumption needs, according to past experiences and modelling results.

The highest water demand in Budapest was recorded in the eighties, and since then, the demand has seen a steady decline (Figure 3). As a result of this, the available nominal water production capacity of the wells is significantly higher than the average water consumption. That would provide the necessary safety from an operational point, but seasonal changes of water consumption should not be neglected. In between the minimum levels of consumption in winter and maximum in summer, a $50 \%$ difference in consumption pattern can be regularly observed. The available water production capacity is also a continuously changing value, largely driven by the Danube water level and water temperature at any given water depression level. The lowest production capacity is observed at concurrently low water levels and low water temperatures, whilst the maximum capacity is expected to occur at high water levels and temperatures. The actual water production capacity is limited by the number of non-operational wells (due to maintenance, reconstruction, or water quality problems). Under "average" conditions, one might falsely conclude that the Budapest Waterworks has unnecessary well capacities. However, it first has to be stated that the maximum water demand must be met at any time. In this situation, the most critical engineering task is to make excluded wells functional again in 
the shortest time possible. A viable option would be to operate the not required wells at low capacity, thus optimizing the hydraulic conditions in the large-scale collector pipe and distribution systems.

The ecosystem services provided by the RBF systems rely largely, but not entirely, on microbiological processes. This makes the complete shutdown of the wells risky, as the full operation of the microbiological system involved in microbiological water treatment processes requires time to regenerate and to start up. During such a regeneration period, problems in water quality may occur. Depending on the duration of the idle phase and other factors, the full regeneration of RBF processes can take multiple weeks or even months. From an operational perspective, this situation should be avoided. Consequently, the practice which is commonly followed is that instead of completely switched-off periods, some limited operation is maintained at wells or well groups.

This practice is, of course, limited by the minimum pumping capacity of the built-in pumps. In some extreme periods, there are instances whereby water production cannot be decreased further unless certain wells stop operating - a factor which has its own risks, considering the time requirement to restart. For such cases, the following compromise was developed by the Budapest Waterworks. Based on their location, certain well groups (8-22 wells per group) are designated to be part of the solution. These groups have a minimum inter-well distance, and all the wells within each group are individually operated with submersible pumps (not siphon wells). Based on the requirement, every second well is shut down for a period of $24 \mathrm{~h}$, or occasionally, $48 \mathrm{~h}$. Afterwards, an intermittent operational cycle starts, the operating ones are switched off, and the temporarily idled are restarted. As a result of this intermittent operational mode, in the neighborhood of any switched-off well, there are two operational wells. Hence, some water transport and microbiologically active zones are sustained. Based on the operational experiences, it is stated that the water quality of the intermittently operated wells remains comparable to normal-operation well groups [18].

\subsection{Low-Water Conditions}

Low-water conditions are defined as being when the Danube water level is below $120 \mathrm{~cm}$ (Budapest gauging station). These periods are becoming more frequent, and their duration is increasingly longer (Figure 1). In these situations, the water production capacity decreases, and it can approach the water demands during critical periods. Therefore, these periods are considered as critical.

For the management of these critical periods, Budapest Waterworks has introduced the term, "nominal capacity". Nominal capacity is defined as water volume that can be produced at a given Danube water level and temperature, at which the value of the drawdown (depression) is $200 \mathrm{~cm}$. This number is arbitrarily selected and based on several decades of operational experience, and it is highly site- and system-specific.

During the peak water production period in the 1980s, depression values of $5 \mathrm{~m}$ were frequently observed. In this early period, water quality was not such a high priority as it has recently become. High depression levels resulted in deteriorating water quality, as well as well-clogging by sand intrusion, which physically damaged the filter layers and the structure of the well.

From the beginning of the 90s, the decreasing water demand resulted in lower water production, and thereby lower depression in wells. It was observed that at a depression level of about $200 \mathrm{~cm}$, no sand intrusion occurred, and the water quality improved. This was the basis of the determination of nominal capacity using this specific value. The continuous maintenance of this value requires careful monitoring and process control.

In the case of extreme and long low-water periods that usually occur in August, the depression limit cannot be maintained, and the depression value can even reach $300 \mathrm{~cm}$. In this scenario, intensive water-quality measurements are commenced, and frequent surveillance of the wells is conducted. When problems arise, emergency actions are taken, such as additional disinfection measures, and the spatial distribution of the production is modified. 
During low-water periods, wells must be operated with higher depression levels to ensure the required water supply, which considerably increases the risk of microbiological noncompliance. In extreme cases, this might lead to cease of production in some wells. Therefore, wells that are still in operation have to maintain production with an elevated production load (depression), resulting in increased water quality-related risks.

Mitigation of this challenge is managed by ensuring the necessary reserve water production capacity to avoid overloading the operational wells. A precondition to this is that surplus wells should always be maintained. This is complemented by the reconstruction of the existing wells, where shaft wells are transferred into horizontal wells (Ranney wells). Provision of surplus production capacities will make the RBF system more robust and resilient to climate change and hydrological extremes.

\subsection{Flood Conditions}

Flood conditions are defined as Danube water levels exceeding $550 \mathrm{~cm}$. At this water level, some of the wells and gravitational collector channels become partly or fully covered by water. At flood conditions, the highest operation risk is the intrusion of surface water into the well. Should this occur, the well must be taken out of service unconditionally and immediately. Intrusion risks can be decreased by appropriate maintenance of the technical elements of the wells, with particular attention to the integrity of the well shaft and the water-impermeable layer above the filter zones (well sealing). This requires continuous monitoring and control of the wells, as well as the implementation of a reconstruction program.

The novel elements of the reconstruction program started by the Budapest Waterworks were partly initiated as a result of new flood patterns observed at the Danube. The highest measured flood level was $891 \mathrm{~cm}$ in 2013, whereby the highest recorded water levels were exceeded on two occasions in the past 15 years. Counteracting the floods requires the reconstruction of wells' pump houses and service appliances, along with the relevant elevation of electric equipment. It may seem like a paradox, but in the case of floods, the available reserve wells are also needed, as a result of the sudden closure of intruded wells. Having the appropriate number of reserve wells is of paramount importance in terms of water safety and security.

\section{Well Construction Issues and Adaptation Measures}

The water production capacities of the horizontal RBF wells are largely determined by the characteristics of the filtration layers, the diameter and length of the horizontal laterals, and their numbers in a given filtration layer.

According to the facts demonstrated in Sections 3.2 and 3.3, the well load increases in cases of both hydrological extremes, but as a consequence of different causes. Additionally, these modified operational conditions result in damaging of the well structure by inducing filter clogging, which shortens the well life-cycle. To prevent or even avoid such events, three different interventions are available which are presented in the following.

\subsection{Adapted Filter Screen Design to Avoid Sand Intrusion at High Pumping Rates}

Within the RBF system, two velocity ranges can be distinguished along the path travelled by the water. In the first zone, flow velocities are near to the edge of the shoreline till the beginning of the effective zone of depression around the well. In the second zone, velocities are increased from the edge of the zone of depression till the inlet points, resulting in increasing kinetic energies near to the filters of the constructed wells. Entering into the horizontal lateral, the velocity of the inflowing water suddenly decreases, resulting in sedimentation of suspended particles. This phenomenon causes a slow accumulation of sediments.

Clogging of the filter depends on many factors, such as the natural sediment composition around the filter (screen), the volume and quality of the water, operational procedures, and the duration between two cleaning periods. As the operational time goes on, the clogging increases and the 
volume of produced water decreases. As a result, producing the same volume of water requires higher depression levels. It is concluded that the water production capacity at a given horizontal well provides the same volume of water referring to the same filtration surfaces, irrespective of the technical design of the horizontal laterals of the well.

Budapest Waterworks operates 217 horizontal collector wells (Figure 4). At the beginning, the wall of the laterals was made of slotted carbon steel filters. Laterals were horizontally extruded into the aquifer. The walls of the laterals were slotted, resulting in filter voids of approximately $14 \%$ of the total surface of the lateral.

Recently, a new design was introduced to horizontal laterals, where the bridge-slotted filters are made of stainless-steel. The size of the surface formed on both sides of the so-called "ear" provides a useful permeable surface of the bridge. After perforation, the plate is formed by a longitudinal welding tube. One end of the tube is cushioned to provide lateral flow. The open inflow area of bridge-slotted filters is approximately $21 \%$ of the total surface.

Due to the geometry of the bridge-slotted filter, the direction of velocity changes in the inflow, and thus significantly reduces the inflow of solids from the well's environment. While slotted filters can hold a grain diameter above $6 \mathrm{~mm}$, the bridge-slotted filter provides effective protection against particle diameters down to $3 \mathrm{~mm}$ due to its two-sided slit surface.

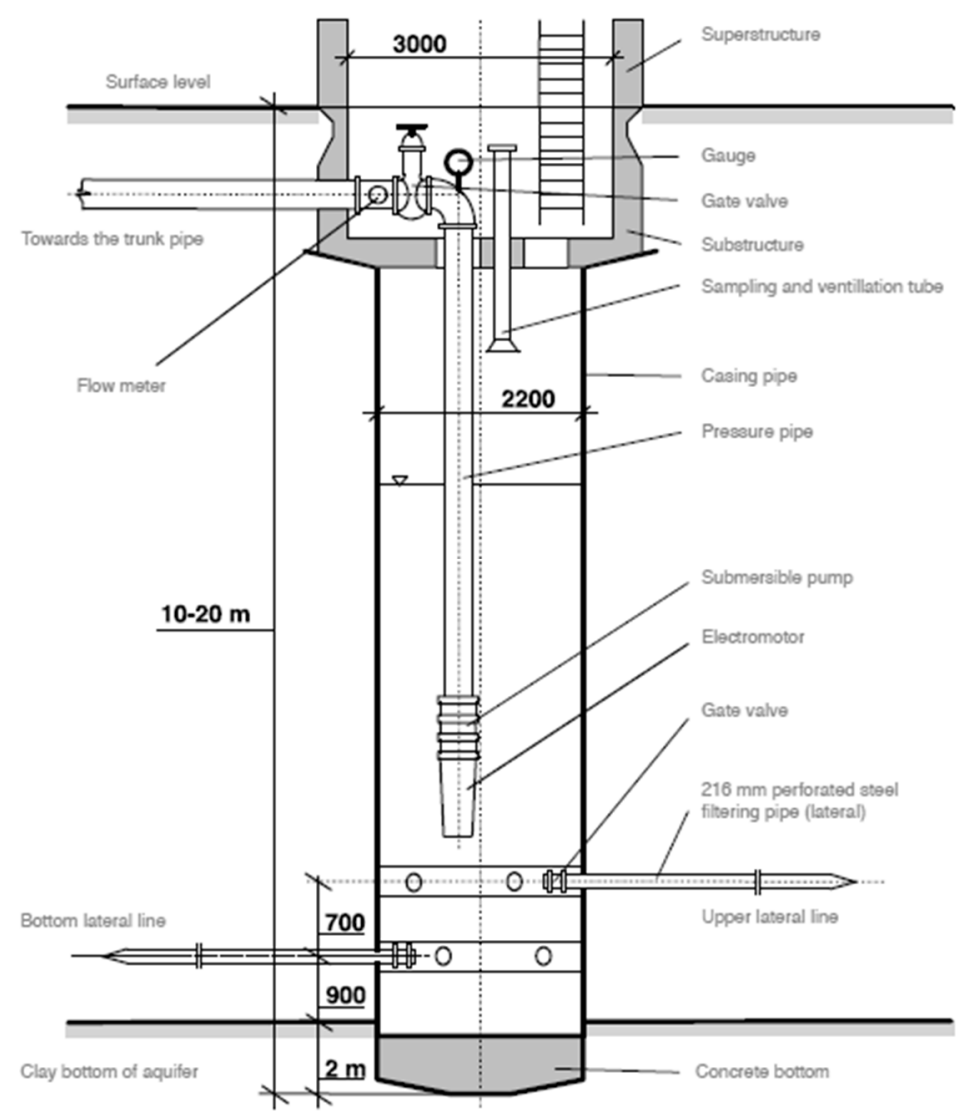

Figure 4. Schematic view of a horizontal collector well.

The deviation of the pipe direction is influenced by the bending stiffness of the tube and the structure of the soil. Technically, the bending stiffness can vary, which is the product of the second torque and modulus of elasticity of the tube. Secondary torque depends on the pipe wall thickness and the fourth power of the material from the distance to the center of gravity of the tube.

The material properties do not change because the bridge design does not involve any material loss. In the case of a bridge-slotted filter, the material distance is increased by extruding the bridge outward: $21 \%$ of the material moves away from the center of gravity by forming a bridge of $3 \mathrm{~mm}$ 
thickness. Thus, the bending stiffness of the slotted pipe is smaller than that of a bridge filter tube of the same diameter, with a higher risk of reversing under pressure.

\subsection{Optimal Well Rehabilitation/Filter Cleaning Frequencies}

Rehabilitation frequencies are based on operational practice and have been determined empirically. In general, the typical cleaning frequency is 7-8 years. Based on practical knowledge, the cycle cannot exceed 10 years. This time length results in massive cementation on the laterals that cannot be removed, with the exception of carbon steel laterals; however, there the cost of removing cementation is extremely high too. As the deterioration of the filter layer is a function of the well operation (velocity of the bank filtrate, volume of produced water), a production load-based cleaning cycle has been developed. The operational data and the amount of produced water have been examined and compared with the nominal capacity for each horizontal well, and the rehabilitation frequencies were also determined (Table 1).

Table 1. Horizontal well-filter cleaning frequencies.

\begin{tabular}{ccc}
\hline Ratio of Production Load and Nominal Capacity in \% & Cleaning Frequency in Years \\
\hline$\geq 80$ & $\geq 65$ & 6 \\
\hline$<80$ & $\geq 50$ & 7 \\
\hline 655 & $\geq 30$ & 8 \\
\hline$<50$ & & 9 \\
\hline$<30$ & & 10 \\
\hline
\end{tabular}

Besides the production load, the following two criteria have been considered: wells that are in operation only at peak demands have a 10-year cycle; strategically important wells have a 7-year cleaning frequency. By applying these criteria and considering the number of wells, the average cleaning cycle has been determined at 7.88 years, which means 29 wells need to be reconditioned annually. This program has to be revised every other year, as operational needs and circumstances might change. Table 2 shows the determined and applied cleaning frequency distribution.

Table 2. Distribution of well rehabilitation frequencies at Budapest.

\begin{tabular}{cc}
\hline Cleaning Frequency in Years & Number of Wells \\
\hline 6 & 11 \\
\hline 7 & 102 \\
\hline 8 & 23 \\
\hline 9 & 9 \\
\hline 10 & 80 \\
\hline Total & 225 \\
\hline
\end{tabular}

\subsection{Shaft Well Transformation into Horizontal Wells}

The Sziget I. well group with nine shaft wells is located at the southernmost point of the Szentendre Island on the right bank of the Danube, between 1657-1658 km (Figure 2). The wells were constructed between 1897-1899. Considering that they are situated close to the network inlet point, their strategic importance is obvious as they are less prone to raw water infiltration in the collecting pipes during floods. By redesigning these shaft wells, higher production capacities can be achieved.

At the bottom of the reinforced concrete, where cylindrical shaft wells do not reach the impermeable layer, they hang on an "I" girder supported by two redwood stilts embedded into the substratum. Therefore, the shaft well and the filtering bell can be considered as a reinforced structure. 
A gravel layer-or a casing shoe — can be found at the bottom of the well, 1.5-2 $\mathrm{m}$ above the bottom of the aquifer. This hinders the intrusion of the sandy-gravel aquifer material into the filtering bell. This solution is widely used under such conditions. In theory, a larger filtering area can be achieved by tapping the bottom of the well than applying a casing reaching down to the bottom of the aquifer.

At the lower part of the reinforced concrete shaft, or the so-called "bell", there is a slotted iron cylinder which is $5 \mathrm{~m}$ in diameter and 3-6 $\mathrm{m}$ in length. The $2.8 \mathrm{~m}$ high cylindrical structure above the bell was constructed according to contemporary concrete technology. Instead of the mesh structure applied nowadays or the reinforcing ironing, six steel rods placed at every $1.5 \mathrm{~m}$ ran along the shaft casing, fixed to the narrowing of the filtering bell. At every meter, a flat steel ring also consolidated the vertical steel rods. This was the complete reinforcement of the well shaft.

The wells are protected by a cast-iron cover on the top of a stone-paved protection cone that was raised above the maximal flood-water level. The vent hole and the sampling tube can be found on the well cover.

The aim of the shaft well redesign is to renew the well structure. The technology involves structural transformation, where a DN 2200 well shaft is installed into a DN 3000 shaft well. The laterals are extruded beneath the previous well screen, but above the bottom of the aquifer. The distance between the bottom of the aquifer and the bottom edge of the screen is $0.7-1.5 \mathrm{~m}$, so the laterals have to fit within this range. The length of the stainless-steel laterals is $30 \mathrm{~m}$, uniformly with a diameter of $200 \mathrm{~mm}$. The laterals have a bridge-slotted structure which has been described in detail above, except for the first $5 \mathrm{~m}$ of the laterals—situated on the well-shaft side- that has a plain surface. For all wells, one lateral is perpendicular to the river, and two laterals are placed at $60^{\circ}$ and $120^{\circ}$ to the Danube. The new well-shafts are raised above the maximal flood level, and the casing is closed by cast-iron covers, but buildups are also feasible. After reconstruction, the same water quantity can be produced, while the operation and the water quality can be improved.

\section{Conclusions}

From an operational aspect, there are existing solutions that can be adapted at RBF systems to cope with extreme hydrological conditions. The first option for assuring the requested water supply in quantity and quality is the construction of a water treatment plant (which was not necessary so far). The second option is to maintain reserve well capacities, ensuring appropriate water quality. Having considered the characteristics of the existing water reserve capacities, as well as the historical background and the financial feasibility, Budapest Waterworks has chosen the second option.

Due to the particularities of RBF, appropriate water quality can be assured even under extreme hydrological conditions by avoiding well overloading. The necessary water volume is produced by operating more wells, thereby optimizing the load across all wells. This also explains the importance of having sufficient reserve wells available. The conditions require to keep these wells in operation, as the microbiological processes might need several weeks, or even months to be established.

Experience based on several decades of research and practical application led to the conclusion that reserve well capacities should fulfil at least $30 \%$ of the total production capacity in the case of extreme hydrological conditions. This figure is based on the particularities of Budapest Waterworks operations. In a broader and more general perspective, a decision on adaptation measures should be made based on investment costs of new wells, maintenance and cleaning interval costs of existing ones, operational costs, public health and technical risks (failures), and changing hydrological conditions.

Author Contributions: Z.N.K., B.L. and E.F. reviewed previous literature and prepared the article draft. E.S. supervised and provided documents related to Section 4.

Funding: The article was prepared within the AquaNES project to synthetize all available information on well operation. This project has received funding from the European Union's Horizon 2020 Research and Innovation Program under grant no. 689450.

Acknowledgments: The authors acknowledge the helpful comments of anonymous reviewers and support from T. Grischek during final paper revision. 
Conflicts of Interest: The authors declare no conflict of interest. The funding sponsors had no role in the design of the study; in the collection, analyses, or interpretation of data; in the writing of the manuscript, and in the decision to publish the results.

\section{References}

1. Haines, A.; Kovats, R.S.; Cambell-Lendrum, D.; Corvalan, C. Climate change and human health: Impacts, vulnerability and public health. Public Health 2016, 120, 585-596. [CrossRef] [PubMed]

2. Gollnitz, W.D.; Whitteberry, B.L.; Vogt, J.A. Riverbank filtration: induced infiltration and groundwater quality. J. Am. Water Works Assoc. 2000, 96, 98-110. [CrossRef]

3. Davidesz, J.; Debreczeny, L. Long-Term Sustainability of RBF Systems from Aspects of Availability and Capacity. Presented at the MAVÍZ Conference, Sopron, Hungary, 11-12 June 2009. (In Hungarian)

4. Merkel, W.; Leuchs, W.; Oldenkirchen, G. Challenges of Global Climate Change for the Water Supply and Distribution in Germany: Experience Report. In Handlungsfelder und Forschungsbedarf, Proceedings of Mülheimer Wassertechnisches Seminar, Mülheim, Germany, 20 November 2007; IWW Wasser Zentrum: Mülheim, Germany, 2007; Volume 46, pp. 1-16.

5. Schubert, J. How Does It Work? Field Studies on Riverbank Filtration, Proceedings of the International Riverbank Filtration Conference, Dusseldorf, Germany, 2-4 November 2000; Julich, W., Schubert, J., Eds.; Internationale Arbeitsgemeinschaft der Wasserwerke im Rheineinzugsgebiet (IAWR): Düsseldorf, Germany, 2000; pp. 41-55.

6. Christensen, N.S.; Wood, A.W.; Voisin, N.; Lettenmaier, D.P.; Palmer, R.N. The effects of cimate change on the hydrology and water resources of the colorado river basin. Clim. Chang. 2004, 62, 337-363. [CrossRef]

7. Ascott, M.J.; Lapworth, D.J.; Sage, R.C.; Karapanos, I. Impact of extreme flooding on riverbank filtration water quality. Sci. Total Environ. 2016, 554-555, 89-101. [CrossRef] [PubMed]

8. Chiaudani, A.; Di Curzio, D.; Palmucci, W.; Pasculli, A.; Polemio, M.; Rusi, S. Fractal approaches on long time-series to surface-water/groundwater relationship assessment: A Central Italy alluvial plain case study. Water 2017, 9, 850. [CrossRef]

9. Kuriqi, A.; Ardicliouglu, M.; Muceu, Y. Investigation of seepage effect on river dike's stability under steady state and transient conditions. Pollack Periodica 2016, 11, 87-104. [CrossRef]

10. Kuriqi, A.; Ardicliouglu, M.; Muceu, Y. Investigation of the hydraulic regime at the middle part of the Loire River in context of floods and low flow events. Pollack Periodica 2018, 13, 145-156. [CrossRef]

11. Sandhu, C.; Grischek, T.; Musche, F.; Macheleidt, W.; Heisler, A.; Handschak, J.; Patwal, P.S.; Kimothi, P.C. Measures to mitigate direct flood risks at riverbank filtration sites with a focus on India. Sustain. Wat. Res. Manag. 2018, 2, 237-249. [CrossRef]

12. Martin, H.K.; Fuchs, M.P. Runoff conditions in the upper Danube basin under an ensemble climate change scenarios. J. Hydrol. 2012, 424-425, 264-277.

13. Ray, C.; Grischek, T.; Schubert, J.; Wang, J.Z.; Speth, T.F. A perspective of riverbank filtration. J. Am. Water Works Assoc. 2002, 94, 149-160. [CrossRef]

14. Schubert, J. Significance of Hydrologic Aspects on RBF Performance. In Riverbank Filtration Hydrology-Impacts on System Capacity and Water Quality; Hubbs, S.A., Ed.; Springer: Dordrecht, The Netherlands, 2006; pp. 1-20.

15. Doussan, C.; Ledoux, E.; Detay, M. River-groundwater exchanges, bank filtration, and groundwater quality: Ammonium behavior. J. Environ. Qual. 1998, 27, 1418-1427. [CrossRef]

16. Schubert, J. Hydraulic aspects of riverbank filtration-field studies. J. Hydrol. 2002, 266, 145-161. [CrossRef]

17. Vanek, V. Heterogeneity of Groundwater-Surface Water Ecotones. In Groundwater/Surface Water Ecotones: Biological and Hydrological Interactions and Management Options; Gibert, J., Mathieu, J., Fournier, F., Eds.; Cambridge University Press: Cambridge, UK, 1997; pp. 151-161.

18. László, B. Assessment of River Bank Filtration in Changing Environmental and Operational Circumstances; WQ III Program, Final Report, Internal Unpublished Document (in Hungarian). Budapest Waterworks: Budapest, Hungary, 2013.

(C) 2018 by the authors. Licensee MDPI, Basel, Switzerland. This article is an open access article distributed under the terms and conditions of the Creative Commons Attribution (CC BY) license (http://creativecommons.org/licenses/by/4.0/). 